\title{
Managing Knowledge For ESAR: An Ontology-Based Approach
}

\author{
Murali Raman, Multimedia University, Malaysia
}

Saravanan Muthaiyah, Multimedia University, Malaysia

Murray E. Jennex, San Diego State University, USA

\begin{abstract}
Most organizations face difficult challenges in managing knowledge for crisis response, particularly in the context of emergency search and rescue (ESAR) initiatives. It is crucial for response effectiveness that such challenges be overcome. Organizational members and numerous stakeholders must share the knowledge needed to plan for such eventualities. They also must be able during a crisis to access relevant plans and communicate about their responses to it. This paper examines the role and relevance of knowledge management ideals (using an ontology based approach) in support of crisis response, in general, and ESAR, in particular.
\end{abstract}

Keywords: Knowledge Management, Crisis Response, ESAR, Ontology, Algorithm

\section{INTRODUCTION}

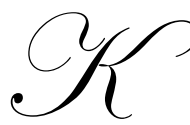

nowledge management, KM, is about capturing knowledge created in an organization and making it available to those who need it to make decisions. Crisis response is about making decisions under stress and time pressure. Emergency Search and Rescue, ESAR, is a major sub-component of crisis response which involves search and rescues efforts that arise due to either man-made or natural emergencies/disasters. While it would seem natural to use KM to support crisis response decision making; a review of the literature pertaining to implementation of KM and KM systems, KMS, finds that the emphasis in KM research is focused on KM impacts on organizational performance and competitive enhancement (Von Krogh 1998; Hackbarth 1998; Davenport and Prusak 1998; Alavi and Leidner 2001, Jennex and Olfman 2005, 2006, Raman et al., 2006). However, events such as the 9/11 terrorist attacks, the London subway bombings, the 2004 tsunami, and Hurricane Katrina have spurred interest in research in crisis/disaster/emergency preparation/response (henceforth referred to as crisis response). This has led to a small but growing body of research focused on examining KM and KMS support for crisis response (Jennex, 2007). Accordingly, the purpose of this paper is to help researchers and managers to better appreciate and understand the relationship between KM, KMS, and crisis response.

The objective of this paper is twofold. First, we discuss if knowledge needed for crisis response can be managed more effectively through KM efforts. Specifically we examine the role and relevance of ontologies as a sub-domain of a KMS to support crisis response efforts. Our second objective is to offer several insights on future research that can- and needs to-be done by researchers that are interested in examining how best an ontology-based framework can be used to support crisis response efforts in the context of ESAR.

The paper proceeds as follows. Section 2 examines fundamental aspects of KM and KM systems. Next we offer an overview of what crisis response is particularly with reference to the core issues involved in crisis management from a decision making perspective. Section 4 provides a brief account of the history and functions of emergency response systems, which leads to a logical discussion about how and why crisis response can benefit from KM principles. Section 6 highlights the role of KM in different phases of a crisis situation. This is followed with several examples of prior work about KM systems applied to the context of crisis response. We end with several suggestions of future research that can be done to extend the ideas that we have presented here. 


\section{KNOWLEDGE MANAGEMENT AND KNOWLEDGE MANAGEMENT SYSTEMS}

A single definition of KM does not exist (Alavi and Leidner, 2001; Nonaka, 1994; Nonaka and Takeuchi, 1995; Nonaka and Konno, 1998). However, Jennex (2005) used an expert panel to generate a composite definition of $\mathrm{KM}$ as the practice of selectively applying knowledge from previous experiences of decision-making to current and future decision making activities with the express purpose of improving the organization's effectiveness. Alavi and Leidner (2001, p. 114) defined a KM System, KMS, as an "IT (Information Technology)-based system developed to support and enhance the organizational processes of knowledge creation, storage/retrieval, transfer, and application." They observed that not all KM initiatives will implement an IT solution, but they support IT as an enabler of KM. Gupta and Sharma (2004) classify KMSs into seven major categories, and this includes among others ontologies.

The purpose of implementing KMS in organizations varies. Von Krogh (1998) takes a business perspective, stating that KMS help increase competitiveness. Hackbarth (1998) suggests that KMS lead to greater innovation and responsiveness. Davenport and Prusak (1998) provide three reasons why KMS are implemented in organizations: (i) to enhance visibility of knowledge in organizations through the use of maps, hypertexts, yellow pages; directories, etc., (ii) to build a knowledge sharing culture, i.e., create avenues for employees to share knowledge, and (iii) to develop a knowledge infrastructure, not confined to technology solely, but create an environment that permits collaborative work. Work by Hackbarth (1998) and Davenport and Prusak (1998) imply that KMS can support an organization in planning for and dealing with crises.

\section{KNOWLEDGE MANAGEMENT AND ONTOLOGY}

An ontology is a formal specification of a domain of knowledge and provides a shared understanding of that domain of knowledge (Gruber, 1993). It describes concepts and relationships and makes them machine processable and understandable. In terms of formality, there is a spectrum of formal specification (see Figure 1). At one extreme (left side of the spectrum), there are lightweight ontologies that may consist of terms only, and at the other end (right side of the spectrum), there are more formal ontologies and inferences. There are various definitions for ontologies such as "a specification of conceptualization" and "an abstract model of how a domain is perceived". The former implies that ontologies provide explicit names and definitions for the concepts and relationships. The latter shows how an explicit existence of such shared perspectives makes it possible for both humans and software robots (i.e. softbots) to collaborate by ensuring that everybody makes the same distinctions and use the same terms in the same context (Fox et al., 1998). This is made possible with the advent of data interchange formats such as NTriples, RDF (Resource Description Framework), Turtle (Terse RDF Triple Language) and OWL (Web Ontology Language).

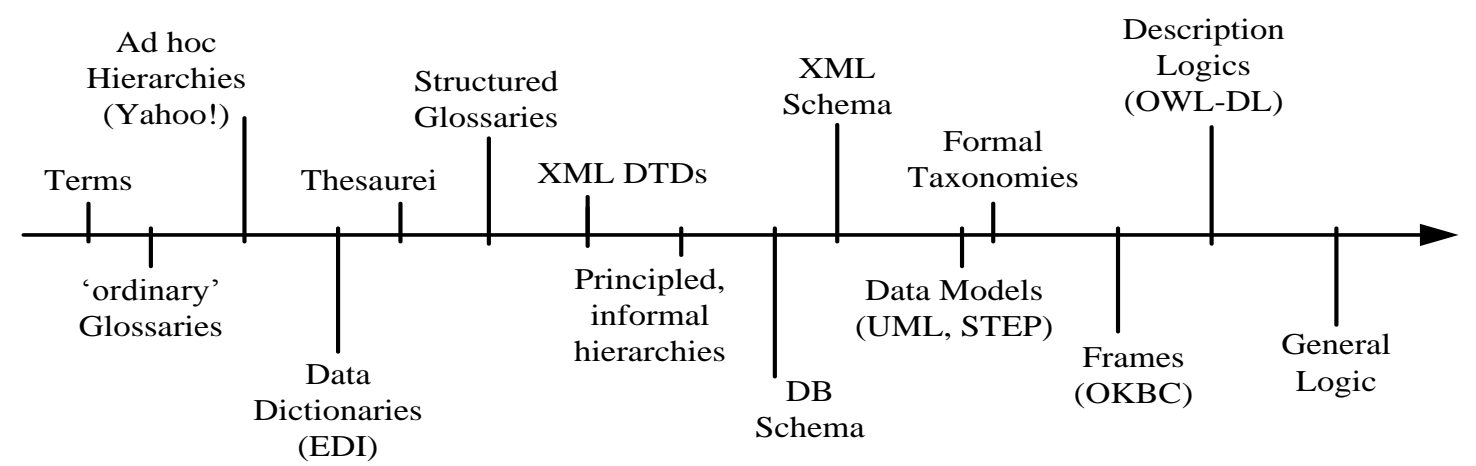

$\begin{array}{ccc}\text { Glossaries \& Data } & \text { Thesauri, } & \text { MetaData, XML } \\ \text { dictionaries } & \text { Taxonomies } & \text { Schemas, \& Data } \\ & \text { Models }\end{array}$

Figure 1: Kinds of Ontologies (Uschold \& Gruninger, 2004) 
Ontologies have been found to be useful for:

i. Retrieving the explicit knowledge from documents and providing the means to semantically annotate data of an OWL document [Alani et al., 2003; Gibbins et al., 2003].

ii. Integrating knowledge from multiple sources and facilitating data exchange between knowledgebases [AgentCities.NET, 2000; OntoWeb, 2002].

iii. Ensuring that information provided is consistent and correct. This is achieved by formulating constraint relations on content data [OntoWeb, 2002].

iv. Creating libraries of interchangeable and reusable data models [AgentCities.NET, 2000; OntoWeb, 2002].

v. $\quad$ Reasoning, this is useful for to derive new knowledge from given knowledge [G'omez et al., 2001; On-ToKnowledge, 1999].

\section{CRISIS RESPONSE AND ESAR}

For the purposes of the paper, crises are high stress situations that require organizations to respond in a manner that is different from their normal operating procedures (Turoff, 2002). Patton and Flin (1999) discuss these stresses on emergency managers and how to reduce them. Emergency stressors, in addition to fatigue, include dealing with a complex, unpredictable and dynamic response, time pressure, and communications, dealing with the media, and operating within an integrated crisis management context. Crises are also a series of four phases: situational analysis (SA), initial response (IR), crisis response (ER), and recovery response (RR); and five decision/hand off points: the initiating event (IE), the control event (CE), the restoration event (RE), the normalizing event (NE), and a terminating event (TE). Figure 1 (Jennex, 2007) shows the phases and decision points and includes a general plot of the amount per unit time of immediate responses and decisions that need to be made as a timeline plot following some initiating event, IE. Note that figure 1 (Jennex, 2007) is not drawn to scale and is a generic drawing of a crisis timeline. Also, a TE point is not shown. The TE is for ending the crisis and would occur if the crisis was determined to be false, or if another crisis took precedence, or any event that would cause the cessation of response to the crisis. The TE can occur in any phase and at any time, so for that reason is it not shown.

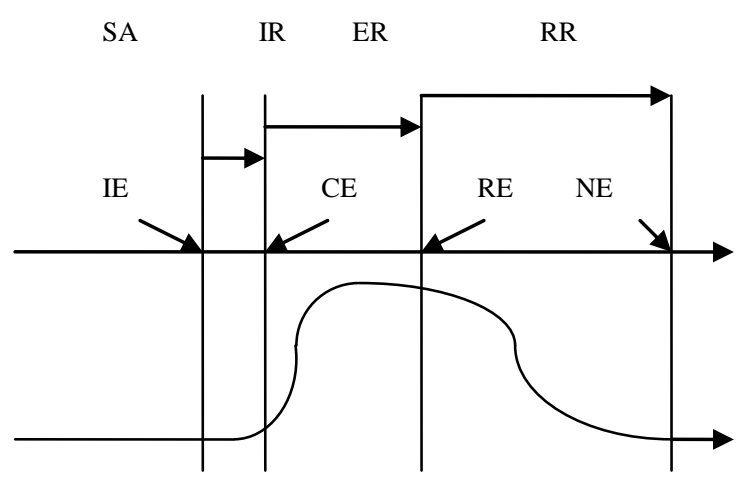

Figure 1, Phases and timeline of activity level for a typical emergency (Jennex, 2007)

Figure 1 (Jennex, 2007) expands on Harrald (2009) and shows that organizations are constantly in a situational awareness, SA, phase which is a data gathering and assessment phase that has a base level of activity. These base level activities are monitoring of a set of predetermined conditions, analysis of these conditions for unusual or pre-identified deviations, identification of an initiating event, IE, and training and preparation of the crisis response team. A crisis begins when during the SA phase an IE is observed. This causes the initial response, IR, phase to be entered. This is expected to be a very short duration phase that consists of confirming the crisis, generating early warning notices, initiating preplanned initial actions, and entering the crisis response plan. In most situations, the IR phase is generally performed by the monitoring team and those individuals at the scene of the crisis. The event response, ER, phase is entered immediately upon assumption of control by the crisis response team 
as indicated by the controlling event, $\mathrm{CE}$, and generally after completion of the immediate response actions and early warning notifications. The CE is generally that point where the crisis control center, CCC, is declared open and the center for the control and coordination of response activities.

The ER phase implements the crisis response plan and begins coordinating responders and other resources. Additionally, this phase is the command and control phase that requires the crisis response team to monitor conditions and to coordinate response accordingly. This phase rises to the peak activity level. This phase ends with the restoration event, RE. The RE is the point where the crisis response team concludes that the crisis conditions are over or are under control and crisis response actions are no longer needed and the crisis control center can cease command operations. At this point, the crisis enters the restoration and recovery, RR, phase. This phase confirms the crisis is under control, controls and coordinates long term actions and reconstruction, guides the organization back to normal conditions, and identifies and captures lessons learned. This phase has a declining level of activity and concludes when the normalizing event, NE, is announced. The NE is the point where all crisis response actions are completed, long term crisis response actions and a base level of reconstruction is completed, the crisis response team is secured, and the organization returns to normal operating procedures and the routine SA phase.

Each of these phases has their own stresses and support needs. To reduce these stresses, crisis response plans and systems should be based on operational demands, tested regularly, and have resources allocated. These plans should not be based on implicit and untested assumptions that reflect routine operational requirements and conditions as plans based on assumed capabilities are less effective than anticipated and will increase ad hoc demands on managers. Working in teams is required during crises and having a well trained, experienced team will reduce the impact of team dynamic stressor. Additionally, crises may require inter agency coordination and dealing with interagency conflict and terminology increases stress.

These stresses can be reduced if these agencies are integrated in their response and participants train together so that they are familiar with each other and comfortable with the integrated crisis response plan. Finally, communication systems are necessary for getting the right information to the right people, but they will not reduce stress unless participants are trained and practiced in their use. In addition to the stresses identified by Patton and Flin (1999), Bellardo, Karwan, and Wallace (1984) identify the stress of decision-making during crisis response and recommend the creation of a Crisis Response System to assist decision makers.

\section{CRISIS RESPONSE AND ONTOLOGY - WHY IS KM RELEVANT?}

Crisis Response Systems are used by organizations to assist in responding to a crisis situation. These systems support communications, data gathering and analysis, and decision-making. Crisis Response Systems are rarely used but when needed, must function well and without fail. Designing and building these systems requires designers to anticipate what will be needed, what resources will be available, and how conditions will differ from normal. A standard model for a Crisis Response System is from Bellardo, Karwan, and Wallace (1984) and identifies the components as including a database, data analysis capability, normative models, and an interface. This model is only somewhat useful as it fails to address issues such as how the Crisis Response System fits into the overall crisis response plan, Crisis Response System infrastructure, multiple organization spanning, knowledge from past emergencies, and integrating multiple systems. Additionally, many organizations do not address the need for a Crisis Response System until a crisis happens, and then, only for a few months until something more pressing comes up (Jennex, 2003). The result is that many organizations have a Crisis Response System that may not be adequate.

Prior to the establishment of the Homeland Security Department, the task of managing information pertaining to crisis situations and crisis management in the United States was under the jurisdiction of the Office of Emergency response (OEP) (Turoff, 1972). The information requirements for the OEP were largely handled by a group of consultants from both business and academia. Over time, the OEP recognized that a system that could provide timely and relevant information to crisis responders was needed (Turoff, 1972). In 1970, twenty-five people working on crisis response were able to collaborate via a computerized Delphi system (Turoff, 1972). Computerized Delphi techniques can be administered via the web today (see for example Cho and Turoff, 2003 and Turoff and Hiltz, 1995). 
In 1971, the OEP was assigned the task of monitoring a new form of crisis called the "Wage Price Freeze" (Turoff et al., 2004). This new role for the OEP included among others, to "monitor nationwide compliance, examine and determine requests for exemptions and prosecute violations" (p. 5) in relation to wage and price changes in the economy. This led to the advent of a flexible system called the Emergency Management Information System and Reference Index (EMISARI). EMISARI was a system designed to facilitate effective communication between people involved in monitoring the Wage Price Freeze situation. The system was designed to integrate people and data into a common platform that could be updated regularly by people who were non-technical administrators (Turoff et al., 2004). The EMISARI system was flexible and enabled several hundreds of people to collaborate in responding to a crisis (see for example Rice 1987, 1990 and Turoff, 2002).

Jennex (2004) classifies crisis management information systems as Emergency Information Systems (EIS). He defines an EIS as any system that is used "by organizations to assist in responding to a crisis or disaster situation" (p. 2148). Jennex further adds that an EIS should be designed to: support communication during crisis response; enable data and gathering analysis; and support decision-making. Lee and Bui (2000) documented vital observation with the use of EIS during the massive earthquake that hit Kobe, Japan, several years ago.

Key lessons for crisis management system designers based on Lee and Bui's work are as follows. Relevant information should be included in the crisis response system prior to the actual crisis situation. This is to ensure that crisis responders have sufficient information to guide the decision-making processes in responding to a crisis. Lee and Bui (2000) imply that the task of gathering relevant information to support crisis response should be incorporated into part of the crisis response strategic initiative. Information from prior experiences should become part of the crisis management system. The system should somehow be able to capture both tacit and explicit knowledge about how prior crisis situations were dealt with. Lessons, which are learned, can be used to guide future action. Lee and Bui (2000) in this regard imply that the design of any crisis response system should support some form of organizational memory component.

In addition to designing relevant systems features to support crisis planning and response, researchers suggest that successful implementation of any crisis management system is contingent on how well people are trained to use such systems (Patton and Flin, 1999; Turoff, 1992; Lee and Bui, 2000). Patton and Flin, for instance, suggest that crisis management systems be incorporated into crisis response related activities such as training, simulations, drills, and evacuation exercises. Turoff (1992) states that crisis management systems that are not normally used will not be used when an actual crisis situation occurs.

The majority of post $9 / 11$ literature on crisis management is confined within the realm of commercial entities (Braveman, 2003). Developments within the domain of crisis management information systems have accelerated over the past few years, particularly after the 9/11 events (Campbell et al., 2004). The authors accurately mention that issues such as resources, expertise, and personnel should be addressed at the onset, prior to designing crisis management systems within the context of local and state level communities. They call for development of "a generic set of requirements" (p.2) that can be used by both the state and local authorities to support crisis planning and response. The researchers however do not base their study on any particular theoretical foundations. Campbell and associates (2004) examine the effect of asynchronous negotiation given "a structured task and a specified negotiation sequence" (p. 3), in the context of crisis responders.

\section{HOW IS ONTOLOGY LINKED TO KM?}

In a dynamic and knowledge-intensive environment, acquiring, sharing and dissemination of knowledge is of great importance. Ontologies provide the vocabulary necessary for humans and software agents to run queries and make assertions for data that would then be used to capture, share and disseminate knowledge in a community of agents and humans. Several components are necessary when new knowledge is discovered and when existing knowledge is updated. Especially in the domain of emergency management, maintaining consistency of data is of utmost importance. Emergency management deals with extreme events that can cause injury and potentially kill a large number of people. It provides management of data and knowledge for extensive damage to property, and disruption of the life of a community (Drabek \& Hoetmer, 1991). Recent natural disasters such as Katrina in New Orleans,USA and the tsunami in Southeast Asia have reinforced the need for the development of a comprehensive 
approach to emergency management (Public Safety Canada, 2005). Ontologies are definitely useful in this effort for capturing; sharing and disseminating information in a knowledge-intensive environment such as this.

Comprehensive Emergency Management (COM) refers to the capacity for handling emergency tasks in all phases such as mitigation, preparedness, response and recovery. This is also covers types of disaster agents and coordinating the efforts and resources of all players - nongovernmental organizations, government agencies and private sectors- involved (Britton, 1999). One of the major challenges in emergency management is the absence of a shared common understanding of concepts and their meanings to describe emergency related data (Britton, 1999). This is referred to as the data heterogeneity problem and as such interoperability between information technologies must be devised for better emergency preparedness. Ontologies are useful in mitigating these issues.

\section{AN ONTOLOGY APPROACH FOR ESAR}

Matheus et al. (2003) provides an example of an ontology for situation awareness. Based on their formal definitions generic core concepts can be developed for domain specific ontologies. Wenjun et al. (2005) uses ontologies for semantic annotation of emergency events. It is used in emergency situations where people need to find the most matched cases with the current events. (Liu \& Fang, 2003) have devised a task ontology for emergency response to debris-flow and supports modeling of activities that are represented in Petri nets. Hoogendoorn et al. (2005) have tried to formally specify disaster plans by using organizational models to conceptualize the structure and dynamics of disaster plans. The use of formal languages with the aid ontologies has enabled analysis and comparison of disaster plans.

After reviewing related work in this area, we believe that in designing an ESAR ontology, we must give priority to emergency and disaster related vocabulary of entities, classes, properties, functions and their relationships with each other. ESAR ontologies should provide a common understanding of emergency, search and rescue as well as facilitate knowledge sharing and reuse among all entities that are involved such as firefighters, homeland security, navy, army, air-force, hospitals, medical personnel, police, civil workers and those who are mending and recovering lifelines. The convergence of the following types of ontologies is necessary for ESAR:

i. $\quad$ Domain ontologies - to represent a target domain such as emergency, search and rescue.

ii. Generic ontologies - to capture temporal knowledge about time, space and events.

iii. Method ontologies - to describe specific tasks such as diagnosis and treatment.

iv. Metadata ontologies - describes existing content of on-line information sources

\section{AREAS FOR FUTURE RESEARCH}

In the past decade, particularly post the September 11 incident; many studies have examined the role and relevance of Information Systems in the context of disaster management and response efforts (Kostman 2004). More recently, researchers have examined the application of KMS to aid disaster response and crisis planning, in an organizational or community wide context (Jennex, 2007, 2006, 2005, 2004, Raman et al. 2006). However, limited work has been done to establish a link between ontologies (as a subset of a KMS), and crisis response efforts. In this context, future work and projects can be carried out to better ascertain the following:

- $\quad$ The role of ontologies to ESAR initiatives - particularly by virtue of case studies and/or other forms of empirical investigation

- $\quad$ Actual development of an ESAR ontology that is tested in a real world scenario to aid such efforts, using again either a case based approach or an action research methodology

- Design and development of ontology for ESAR using the design science approach with the objective creating either simulation model, prototype, work process of other outputs, that offer a more effective and efficient approach for ESAR, based on present day KM tools and technologies. 


\section{CONCLUSION}

Emergency response in the United States of America, USA, is evolving from something that was locally handled to something that is standardized under Federal control. The USA implemented the National Incident Management System, NIMS, in 2004. NIMS established standardized incident management protocols and procedures that all responders are to use to conduct and coordinate response actions (Townsend, 2006). Townsend (2006) discusses lessons learned from Katrina that include communications infrastructure, knowledge about emergency response plans, integration of civilian and military response activities, and critical infrastructure and impact assessment issues. Review of these issues suggests there were failings in the emergency response systems that could have been prevented only if effective KM systems were in place.

This paper helps to bring to the light some of the core issues that lie at the heart of Emergency Management systems, in particular ontology-based systems that can be used to acquire, share and disseminate knowledge related to Emergency Management. It highlights how a common understanding of concepts can be achieved through ontology-based KM efforts. Specifically it examines the role and relevance of KMS to support crisis response efforts. Moving on, future researchers can enhance KM systems related research by mapping this to the concept of ESAR and examine how ontologies can be used to guide more effective design, development and ultimately use of KM systems in support of ESAR efforts.

\section{REFERENCES}

1. AgentCities.NET. IST project IST-2000-28384 Agentcities, 2000. http://www.agenticities.net/.

2. Alani, H., S. Kim, D. Millard, M. Weal, W. Hall, P. Lewis, and N. Shadbot. Automatic ontology based knowledge extraction from web documents. IEEE Intelligent Systems, 18(1):14-21, 2003.

3. Alavi, M. and Leidner, D.E. (2001). Review: Knowledge Management and Knowledge Management Systems: Conceptual Foundations and Research Issues. MIS Quarterly, 25(1), 107-136.

4. Bellardo, S., Karwan, K.R., and Wallace, W.A., (1984). Managing the Response to Disasters Using Microcomputers. Interfaces, 14(2), 29-39.

5. $\quad$ Braverman, M. (2003). Managing the human impact of crisis. Risk Management, 50(5), 10-.

6. Britton, N. R. (1999). Whither the emergency manager? International Journal of Mass Emergencies \& Disasters, 17(2), 223-235.

7. Campbell, C. L., DeWalle, B. V., Turoff, M., \& Deek, F. P. (2004). A Research Design for Asynchronous Negotiation of Software Requirements for an Emergency Response Information System. Paper presented at the Americas Conference on Information Systems, New York City.

8. Davenport, T.H. and Prusak, L. (1998). Working Knowledge. Harvard Business School Press.

9. Drabek, T. E., \& Hoetmer, G. J. (1991). Emergency management: Principles and practice for local government. Washington, D.C.: International City Management Association.

10. Fox, M. S., Barbuceanu, M., Gruninger, M., \& Lin, J. (1998). An organization ontology for enterprise modelling. In M. Prietula, K. Carley \& L. Gasser (Eds.), Simulating organizations: Computational models of institutions and groups (pp. 131-152): AAAI Press.

11. G'omez-P'erez, A., and O. Corcho. Ontology languages for the semantic web. IEEE Intelligent Systems, 17(1):54-60, 2002.

12. Gibbins, N., S. Harris, and N. Shadbolt. Agent-based semantic web services. Paper presented at the Twelfth International World Wide Web Conference (WWW2003), Budapest, Hungary, 2003. ACM Press.

13. Giunchiglia, F. and Zaihrayeu, I. "Making peer databases interact - a vision for an architecture supporting data coordination." Proceedings of the Conference on Information Agents, Madrid, September 2002.

14. Gruber, T.R., Toward Principles of Design Ontologies Used for Knowledge Sharing, 1993.

15. Gupta, J. D., \& Sharma, S. K. (2004). Creating Knowledge Based Organizations: IDEA Group Publishing.

16. Hackbarth, G. (1998, August 1998). The Impact of Organizational Memory on IT Systems, paper presented at the Fourth Americas Conference on Information Systems.

17. Harrald, J.R., (2009). Achieving Agility in Disaster Management. International Journal of Information Systems for Crisis Response and Management, 1(1), pp. 1-11. 
18. Hoogendoorn, M., Jonker, C. M., Popova, V., Sharpanskykh, A., \& Xu, L. (2005). Formal modelling and comparing of disaster plans. Paper presented at the Proceedings of the Second International Information Systems for Crisis Response and Management (ISCRAM), Brussels, Belgium.

19. Hoogendoorn, M., Jonker, C. M., Popova, V., Sharpanskykh, A., \& Xu, L. (2005), Formal modelling and comparing of disaster plans, Second International Information Systems for Crisis Response and Management (ISCRAM), Brussels, Belgium.

20. Jennex, M.E. and Olfman, L., (2005). “Assessing Knowledge Management Success” International Journal of Knowledge Management, 1(2), pp. 33-49.

21. Jennex, M.E. and Olfman, L., (2006). "A Model of Knowledge Management Success" International Journal of Knowledge Management, 2(3), pp. 51-68.

22. Jennex, M.E., (2003). Information Security in the Era of Terrorist Attacks. Information Resource Management Association International Conference Panel.

23. Jennex, M.E., (2004). Emergency Response Systems: The Utility Y2K Experience. Journal of IT Theory and Application (JITTA), 6(3), 85-102.

24. Jennex, M.E., (2005). Knowledge Management Systems. International Journal of Knowledge Management, 1(2), pp. i-iv.

25. Kostman, J. T. (2004). 20 Rules for Effective Communication in a Crisis. Disaster Recovery Journal. 17(2), 20.

26. Lee, J., \& Bui, T. (2000). A Template-based Methodology for Disaster Management Information Systems. Paper presented at the Hawaii International Conference on Systems Science, Hawaii.

27. Liu, W.-Y., \& Fang, K. (2003). Using IDEF0/petri net for ontology-based task knowledge analysis: The case of emergency response for debris-flow, the 39th Annual Hawaii International Conference on System Sciences, 2006.

28. Matheus, C. J., Kokar, M. M., \& Baclawski, K. (2003). A core ontology for situation awareness. Paper presented at the The 6th International Conference on Information Fusion.

29. Matheus, C. J., Kokar, M. M., \& Baclawski, K. (2003). A core ontology for situation awareness, 6th International Conference on Information Fusion.

30. Nonaka, I., \& Konno, N. (1998). The concept of "ba": Building a foundation for knowledge creation. California Management Review, 40(3), 40-54.

31. Nonaka, I., \& Takeuchi, H. (1995). The Knowledge-Creating Company? New York: Oxford University Press.

32. On-To-Knowledge. IST project IST-1999-10132 On-To-Knowledge, 1999. http://www.ontoknowledge.org/.

33. OntoWeb, 2002] OntoWeb. IST project IST-2000-29243 OntoWeb, 2002. http://www.ontoweb.org.

34. Patton, D., \& Flin, R. (1999). Disaster Stress:An Emergency Management Perspective. Disaster Prevention and Management, 8(4), 261-267.

35. Public Safety Canada. (2005). From http://www.publicsafety.gc.ca/media/nr/2005/nr20051117-en.asp

36. Raman, M., Ryan, T., and Olfman, L., (2006). Knowledge Management Systems for Emergency Preparedness: The Claremont University Consortium Experience. The International Journal of Knowledge Management, 2(3), 33-50.

37. Rice, R. E. (1987). Information, Computer Mediates Communications and Organizational Innovation. Journal of Communication, 37(4), 65-94.

38. Rice, R. E. (1990). From Adversity to Diversity: Applications for Communication Technology to Crisis Management. Advances in Telecommunications Management, 3(91-112).

39. Turoff, M. (1972). Delphi Conferencing: Computer Based Conferencing with Anonymity. Journal of Technological Forecasting and Social Change, 3(2), 159-204.

40. Turoff, M. (2002). Past and Future Emergency Response Emergency Response Information Systems. Communications of the ACM, 45(4), 38-43.

41. Turoff, M., \& Hiltz, S. R. (1995). Computer Based Delphi Processes. In M. Adler \& E. Ziglio (Eds.), Gazing Into the Oracle: The Delphi Method and Its Application to Social Policy and Public Health (pp. 5688). London: Kingsley Publishers.

42. Turoff, M., Chumer, M., Van de Walle, B., \& Yao, X. (2004). The Design of a Dynamic Emergency Response Management Information Systems (DERMIS). Journal of Information Technology Theory and Application, 5(4), 1-35. 
43. Uschold, M., \& Gruninger, M. (2004). Ontologies and semantics for seamless connectivity. ACM SIGMOD Record, 33(4), 58 - 64.

44. Von Krogh, G. (1998). Care in Knowledge Creation. California Management Review, 40(3), $133-153$.

45. Wenjun, W., Yuelong, W., Fankuo, M., Wei, Y., Yingwei, L., \& zhuoqun, X. (2005, November). The semantic annotation of emergency event cases, First International Conference on Semantics, Knowledge and Grid, 2005, China.

46. Wenjun, W., Yuelong, W., Fankuo, M., Wei, Y., Yingwei, L., \& zhuoqun, X. (2005, November). The semantic annotation of emergency event cases. Paper presented at the First International Conference on Semantics, Knowledge and Grid, 2005, China.

\section{NOTES}


NOTES 